\title{
Use of SAP in the Implementation of the Activities-Based Costs - The Case of Steel Companies
}

\author{
Violeta Maria ISAI ${ }^{\star}$, Caterina NICOARA-OANA ${ }^{\star \star}$
}

\begin{tabular}{l}
\hline \multicolumn{1}{c}{ A R T I C L E I N F O } \\
\hline Article history: \\
Accepted December 2019 \\
Available online December 2019 \\
\hline JEL Classification \\
L86, M11 \\
Keywords: \\
Cost centres, Internal orders, \\
Production orders, Cost settlement
\end{tabular}

\section{Introduction}

Using the cost calculation method in the ERP - SAP system, it requires the definition of the organizational structure for the management accounting module, a closed system in which all the economic operations regarding the costs and revenues are carried out. The primary costs are taken from the financial accounting and are classified by the management accounting perspective. In the control area the internal business transactions are managed, allowing the tracking of the specific information for the monitoring of the costs, of the business decisions and of the sales. Direct and indirect expenses are allocated to various cost objects (cost centers, internal orders). The system then allocates these expenses, until they are collected on final cost recipients, using internal allocation techniques, depending on their source.

\section{SAP organizational structure - an excellent solution in cost control \\ The system operates with the following structural elements:}

The elements of primary cost / income represent the accounts of expenses and incomes in the financial accounting. All expense accounts and the "Stock variation" account are defined as primary cost items of category 01 , which are the basis of allocation from one cost object to another. The other income accounts are defined as income items of category 11 . The revenues are ignored by the system in the iterative calculation of the price of the activities and therefore are not included in the allocation price of the types of activity. The account "Income from the production of fixed assets" is defined as a cost element of category 22 for the settlement of the expenses from the internal investment orders on fixed assets accounts, for the fixed assets realized on its own account.

Secondary cost items are created and managed exclusively in managerial accounting, and on them are identified those expenses that are the subject of internal allocations, such as internal activity allocations, internal order settlements or distribution of expenses. They have nine characters, as follows: 9XX000YYY, where: 9 - constant for identification, XX cost element category, and YYY order number. The cost category is: 21 - for the settlement of internal orders; 42 - for the allocation of transfer expenses; 43 - for the allocation of expenses by types of activities. Example: 943000503 - "Methane gas" distributed by types of activity.

Cost items for internal settlement are used to settle internal orders that are used to collect expenses on repairs, refurbishments and other benefits.

The cost elements for the transfer are used to settle the expenses from the administrative (W-type) and service (H-type) cost centers to the productive (F-type) cost centers. Also, by means of this type of cost elements the expenses of the productive cost centers (of type F) are realized on CO production orders.

\footnotetext{
${ }^{\star},{ }^{\star \star}$ Dunarea de Jos University of Galati, Romania, E-mail address: violeta.isai@yahoo.com (V. M. Isai - Corresponding author)
} 
The cost elements for indirect allocation of activities are used to deduct the expenses from the auxiliary cost centers to the cost centers consuming the activity produced by the first (beneficiaries can be all categories of cost centers).

Cost centers are centers of responsibility in the company, which determines and influences the costs and which have the following functionalities: collect and allocate the expenses; perform the cost planning; delimit responsibilities; realize the production link with the costs; they allow the allocation of the types of activities, thus revealing the specific activities that are produced in a cost center; allow the generation of management reports.

In order to obtain planning and registration information, the cost centers are classified into the following categories: production cost centers $(\mathrm{F})$; ancillary cost center $(\mathrm{H})$; administrative cost center (W).

Each cost center is attached to a hierarchical position, this position usually grouping several cost centers (hierarchical position = group of cost centers). The hierarchy of cost centers contains all the cost centers, therefore it represents the whole company.

The types of activities are units used for the allocation of internal activities in accordance with the mode of use. They are used to allocate the costs from one cost center to another controlling object, based on the number of units of deployed activity. The unit price is used to evaluate the quantity of the activity.

Statistical indicators or distribution keys are measurable quantities that are allocated to cost centers and internal orders, being used as an allocation basis in allocating indirect costs to cost centers.

Internal orders are used to plan, collect, monitor and settle the costs specific to the operations and activities carried out within the company. The system allows internal orders to be controlled throughout the entire life cycle, from creation, to planning and recording current costs, including final settlement. Internal orders are of two types: real and statistical.

The real internal orders collect the expenses for the repairs (current or capital), are settled on cost centers or other orders through a secondary cost element of category 21 "internal settlement", defined in the allocation structure. The closing of the order is realized when the expenses are no longer collected on it. Settlement control parameters are defined in a settlement profile, which allow the settlement of internal orders. For the internal orders defined in the system, the settlement profile 20 - "direct costs" is used, which contains the following parameters as valid recipients: Big Book account, cost center, order, fixed assets, material, profitability segment.

CO production orders are the objects used in the system to collect the expenses for the production of a product, as follows: finished product, semi-manufactured product, production in progress, residual products or spare parts. They represent production orders without the structure of quantities. Therefore, they do not use basic data related to PP module (material lists, technology sheets)

In terms of lifespan, the CO production orders, through which the costs of semi-finished and finished products are tracked, are of two types:

\# permanent orders - open for the coking, agglomeration, cast iron and liquid steel processing phase, as well as all the auxiliary products in these phases: coke gas, tar, granulated slag, bricks, solid cast iron.

* periodic orders - open for continuous casting, hot rolling, cold rolling, galvanizing and longitudinal welding. On each of these phases, CO production orders are opened for each product in the manufacturing program, with the corresponding sales order being specified.

Production orders accrue during the period: raw material expenses; expenses arising from the allocation of activities from productive cost centers; consumption of semi-finished products.

The expenses are reflected as follows:

\# primary cost elements - taken directly from the financial accounting, on cost objects: cost centers, orders.

* secondary cost items - under which those expenses that have been the subject of internal allocations, and which are specific, are identified.

* direct expenses that cannot be identified and allocated on the production order (direct and auxiliary materials), as well as the following indirect costs: expenses on salaries, expenses on depreciation, administrative expenses and other expenses.

Internal orders will collect expenses according to the internal requirements of the company, using the collection of two types of expenses, statistical and real. The real orders are created for the repair and maintenance departments in the metallurgical sector, where all the expenses related to the order are accumulated, and after closing the order, all the expenses are settled on the cost centers that have benefited from the order's performance. Statistical orders mainly accumulate the expenses for the maintenance and repair of the means of transport for the U.E.T.U. In the databases of the statistical orders are entered the cost centers to which they refer, in this way all the records on these orders automatically, being allocated to the respective cost centers.

Closing the orders at the end of the period, when performing the month-end operations, involves the following steps:

* Distribution of the expenses from the common cost centers of the department and administrative, by productive cost centers / internal orders;

\# Distribution of the expenses from the internal orders, on the beneficiary productive cost centers; 
* Distribution of expenses from productive cost centers, on CO production orders;

* Running the settlement of the CO production orders for the calculation of the achieved cost of the materials and their re-evaluation;

* Running the program for calculating the cost differences for produced materials and recording them on the orders in the production flow;

* Analysis of cost differences and, possibly, their correction;

\section{Collection and disposal of maintenance expenditure on cost centers}

Internal orders are used to collect maintenance expenses (maintenance and repairs), which will be settled to the cost centers benefiting from repairs, according to the collection rules.

The groups of cost elements (cost components) are the following:

1. Internal (direct) labour - confirmed hours

2. Indirect wage costs - unconfirmed hours

3. Operating costs

4. Direct purchases - parts and consumables ordered directly from the work order and received on it

5. Spare parts and consumables - parts and consumables consumed from stock

6. External services - third party repair invoices

7. Semi-finished products

The total costs of the maintenance unit include:

* Labour directly productive employees who work effectively on repair orders, within a time limit;

* Labour of directly productive employees who do not actually work on repair orders within a time limit (rest, sick leave, unconfirmed times)

* Wage costs of indirectly productive employees

* Expenses with SDVs and general consumables (Vaseline, screws, etc.)

* Overhead charges: energy, rents, buildings, etc

Cost center A includes all the direct costs necessary for the operation of the maintenance unit:

* The salaries of the directly productive employees based on the salaries paid in the month (including bonuses, provisions). The number of hours represents the hours actually worked, confirmed on work orders (the number of hours for sick leave, rest are excluded, the number of hours allocated to the training activity are included);

* The salaries of indirectly productive employees, which are not registered on the work order: managers, planners - the other structures that do not enter as directly productive;

* Expenses with own vehicles, SDVs, workshops;

* Energy, household administrative expenses, transport, consumed products / semi-finished goods, mechanisms for occupational safety;

These costs are grouped into the cost components: "Internal (direct) labour ", "Indirect wage costs" and "Operating costs".

At the same cost center, the indirect additional costs are collected in relation to the activity of the maintenance center (the share of administrative expenses, department head, staff, other general costs). Then, the cost chapters are calculated and the A cost center is settled, on the work order:

* Internal labour rate: total direct salary expenses, divided by the number of hours actually worked (confirmed on work orders);

* Indirect wage costs: total indirect wage costs + internal labour for own work orders + unconfirmed direct expenses on work orders (rest, sick leave), divided by the number of hours actually worked (confirmed on work orders, without their own);

* Operating costs: total direct costs + total indirect operating costs, divided by the number of hours actually worked (confirmed on work orders, without their own).

Finally, the costs collected on the work order, both those taken directly (direct purchases, parts and consumables, semi-manufactured goods, external services) and indirect (direct labour, indirect salaries, operating costs), are settled on the cost center of repairs that reflect the functional location.

All expenses incurred: Direct purchases - parts and consumables ordered directly from the work order and received thereon, Spare parts and consumables - parts and consumables consumed from stock, External services - Third party repair invoices and semi-manufactured goods - must be budgeted, with respect to the works in the maintenance strategy for the current year.

The settlement of the expenses with the new spare parts, reconditioned spare parts stoked and reconditioned spare parts not stocked, executed at the Spare Parts Factory (SPF), on the local maintenance cost centers in the departments, is realized following the following rules:

* the expenses completed in the chapter man - internal hours, sums the salaries of the workers from the local maintenance + the salaries of the workers from the SPF.

* the number of hours confirmed in the work order contains only the work of the workers from the local maintenance. 
the cost of internal hours = (salaries of workers from local maintenance + salaries of workers from SPF $) /$ number of confirmed hours for workers from local maintenance.

For reconditioning (with stock): replacement of defective parts is made with a value "0" (zero) (a specific type of movement that allows the value to be entered); when SPF consumes these parts for reconditioning, consumption is also rated "0" (zero). The value of the refurbished part is in stock by SPF (at the planned refurbishment price). The department consumes the part at the same price, with some adjustments between the planned price and the current price of the reconditioning, for the internal SPF order.

\section{Conclusions}

Organizational costs need to be known to management so that it can be used as a tool for decision making. Therefore, the cost information needs to be integrated into the management process. This requires a system that can support the management of cost data and therefore control the cost. Considering the technological advances and the increasing complexity of the production systems in many companies, the vision of the decision makers within organizations have changed. Nowadays, there is a wide variety of methods in the field of computing systems, which describe a multitude of different possibilities. The difficulty lies in choosing the best method for each company. SAP is an optimal solution in this regard, because it allows the monitoring and control of information regarding the company's performance, through the following processes: accounting on cost centers, on profit centers, on internal orders, as well as planning and reporting.

\section{References}

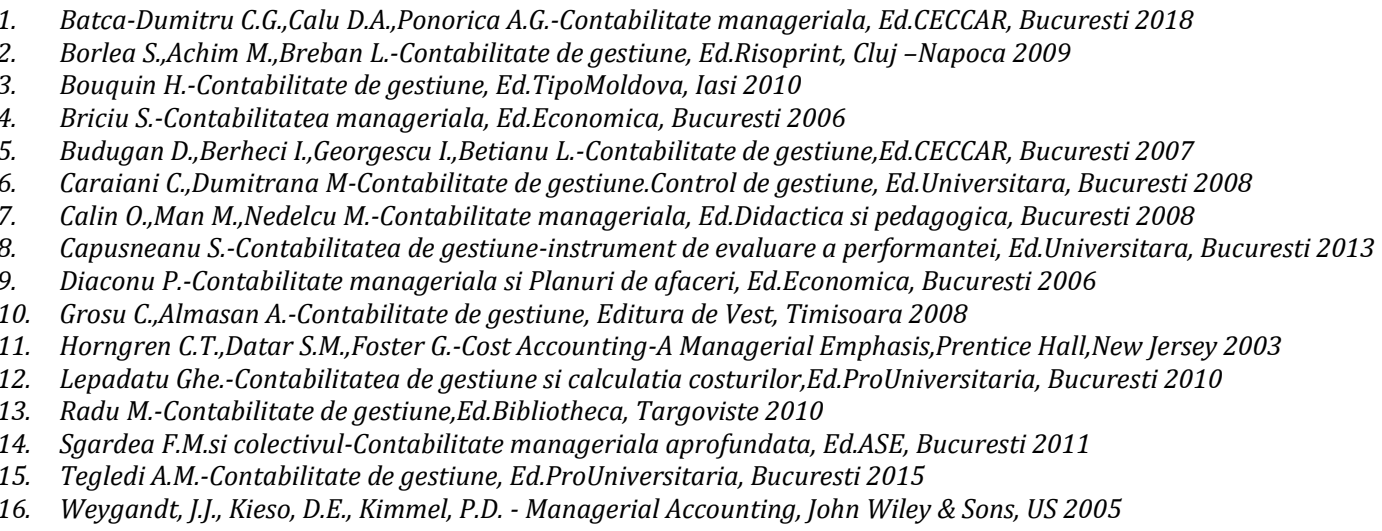

